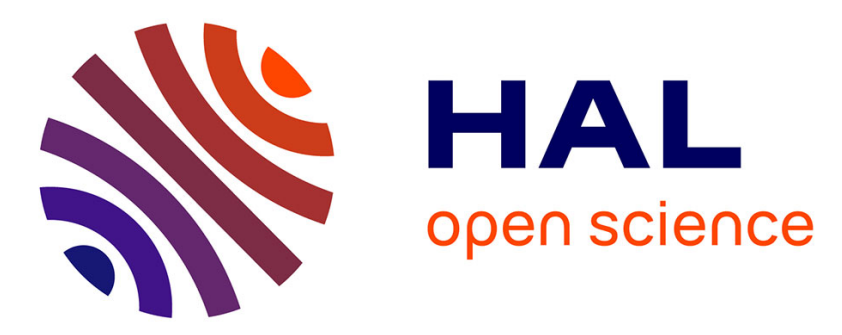

\title{
THE FREELY EXPANDING RING TEST - A TEST TO DETERMINE MATERIAL STRENGTH AT HIGH STRAIN RATES
}

\author{
R. Warnes, R. Karpp, P. Follansbee
}

\section{- To cite this version:}

R. Warnes, R. Karpp, P. Follansbee. THE FREELY EXPANDING RING TEST - A TEST TO DETERMINE MATERIAL STRENGTH AT HIGH STRAIN RATES. Journal de Physique Colloques, 1985, 46 (C5), pp.C5-583-C5-590. 10.1051/jphyscol:1985575 . jpa-00224809

\section{HAL Id: jpa-00224809 https://hal.science/jpa-00224809}

Submitted on 1 Jan 1985

HAL is a multi-disciplinary open access archive for the deposit and dissemination of scientific research documents, whether they are published or not. The documents may come from teaching and research institutions in France or abroad, or from public or private research centers.
L'archive ouverte pluridisciplinaire HAL, est destinée au dépôt et à la diffusion de documents scientifiques de niveau recherche, publiés ou non, émanant des établissements d'enseignement et de recherche français ou étrangers, des laboratoires publics ou privés. 
THE FREELY EXPANDING RING TEST - A TEST TO DETERMINE MATERIAL STRENGTH AT HIGH STRAIN RATES

\author{
R.H. Warnes, R.R. Karpp ${ }^{\star}$ and P.S. Follansbee \\ Los Alamos National Laboratory, P.0. Box 1663, Los Alamos, \\ New Mexico 87545, U.S.A.
}

Résumé - Le test d'expansion de cylindre (ERT) est un test de conception simple pour étudier le comportement des matériaux en grande déformation et pour de grandes vitesses de déformation. Le test est réalisé en plaçant un anneau mince du matériau à étudier dans un processus d'expansion radiale et en mesurant cette vitesse d'expansion. L'anneau est projeté par un explosif ; le test n'est pas devenu populaire à cause des problèmes posés par le lancement de l'anneau par l'explosif, notamment sur les modifications des propriétés par l'onde de choc. Pour déterminer l'aptitude de 7 'ERT à déterminer les propriétés des matériaux, une série d'expériences a étě conçue sur un matériau sévèrement contrôlé (un cuivre revenu sans oxygène). Les anneaux récupérés ont été analysés et leur changement de dureté dêterminé. La comparaison entre les données de T'ERT et celles obtenues avec des essais à $\dot{\varepsilon}=5 \times 10^{3} \mathrm{~s}^{-1}$ à la barre d'Hopkinson indique que la dureté induite par choc est approximativement équivalente à un écrouissage de 5\%. Les données de l'ERT sur ce matériau pour des vitesses de déformation allant jusqu'à $2,3 \times 10^{4} \mathrm{~s}^{-1}$ sont prēsentées.

Abstract - The freely expanding ring test (ERT) is a conceptually simple test for determining the stress-strain behavior of materials at large strains and at high strain rates. This test is conducted by placing a thin ring of test material in a state of uniform radial expansion and then measuring its subsequent velocity- time history. The ring is usually propelled by a high explosive driving system. The test has not become popthlar in the materials property community, however, because there has been some concern about how the launching of the ring sample with an explosively generated shock wave might affect the properties to be measured. To determine the suitability of the ERT for these fundamental investigations, a series of experiments was performed on a carefully controlled material--oxygen-free electronic fully annealed copper. Recovered ring samples were analyzed and the change in hardness determined. Comparisons of the ERT data with that from Hopkinson bar tests at strain rates of about $5 \times 10^{3} \mathrm{~s}^{-1}$ indicate that the shock-induced hardness is approximately equivalent to a strain hardening of $5 \%$. ERT data on this material at strain rates up to $2.3 \times 10^{4} \mathrm{~s}^{-1}$ are presented.

\title{
I - BACKGROUND
}

Since its introduction over two decades ago, the freely expanding ring test (ERT) has shown promise as a simple test for measuring the flow stress in materials deforming in tension at extremely high rates[1,2]. The test technique consists of placing a thin ring of test material in a state of uniform radial expansion, the

‡ Present address: Aerojet Ordnance Co., 2521 Michelle Drive, Tustin, California, 92680 USA. 
ring moving outward without the action of external forces. The radial velocity of the ring decreases, however, because of the action of internal circumferential flow stresses. By measuring the deceleration of the ring, one can infer, through the equation of motion, the magnitude of this stress. The strain and strain rate can also be determined from the measured motion.

The equation of motion of a thin ring undergoing symmetrical radial expansion is

$$
\sigma=-p r r,
$$

where $\sigma$ is the circumferential stress, $\rho$ is the density of the ring material, $r$ is the current radius of the ring, and $r$ is the current radial acceleration. The true strain, $\varepsilon$, and true strain rate, $\dot{\varepsilon}$, are given by

$$
\begin{gathered}
\varepsilon=\ln \left(r / r_{0}\right), \text { and } \\
\dot{\varepsilon}=\dot{r} / r,
\end{gathered}
$$

where $\dot{r}$ is the current radial velocity of the ring.

In the past several years the test has been studied in detail, and many improvements in design, instrumentation, and data analysis have been made $[3,4,5]$. Previous investigators had measured the ring displacement $r(t)$ directly, double differentiated it, and determined the stress through $\mathrm{Eq} .(1)$. This inherently noisy process of double differentiation has been overcome in recent work by measuring the ring velocity $\dot{r}(t)$ directly with a laser velocity interferometer, therefore requiring only a single differentiation and integration to apply Eq. (1). Changes in the design of the experiment have resulted in assuring a symmetric launch of the ring and minimizing its two-dimensional motion during the initial acceleration.

This paper will discuss the current design of the test along with considerations of the choice of materials to be studied, data acquisition, and data analysis. A comparison of data taken with the ERT and the Hopkinson bar test on oxygen-free electronic (OFE) fully annealed copper will be made at a strain rate of about $5 \times 10^{3} \mathrm{~s}^{-1}$.

\section{II - PRESENT DESIGN OF THE TEST}

Figure 1 is a schematic of the ERT. A cylinder of high explosive is centered in a high strength steel driver by foam spacers on each end. Three rings of the material to be studied are machined with an i.r. 1\% less than the o.r. of the driver and carefully pressed onto the driver, insuring good contact between the rings themselves and the rings and the driver. The use of three rings has been shown to greatly reduce the time required for the central ring (the ring to be studied) to achieve the one-dimensional motion necessary for $\mathrm{Eq}$. (1) to be correctly applied. When the explosive is detonated on both ends simultaneously, the rings are driven outward, quickly leaving the stronger driver behind. The driver material is VascoMax 250 with a Rockwell "C" hardness of from 28 to 31 . The addition of steel tubes to each end of the driver to channel explosive gases away from the laser beam path has increased the length of time over which the velocity can be measured by nearly a factor of two and improved the precision of the subsequent data analysis. Dimensions for the "standard" experiment are: driver 0.d., $47.93 \mathrm{~mm}$; driver height, $50.8 \mathrm{~mm}$; ring i.d., $47.47 \mathrm{~mm}$; ring 0. d., $50.34 \mathrm{~mm}$; center ring height, $1.44 \mathrm{~mm}$; outer ring height, $2.87 \mathrm{~mm}$; gas channet length, $76.2 \mathrm{~mm}$. 


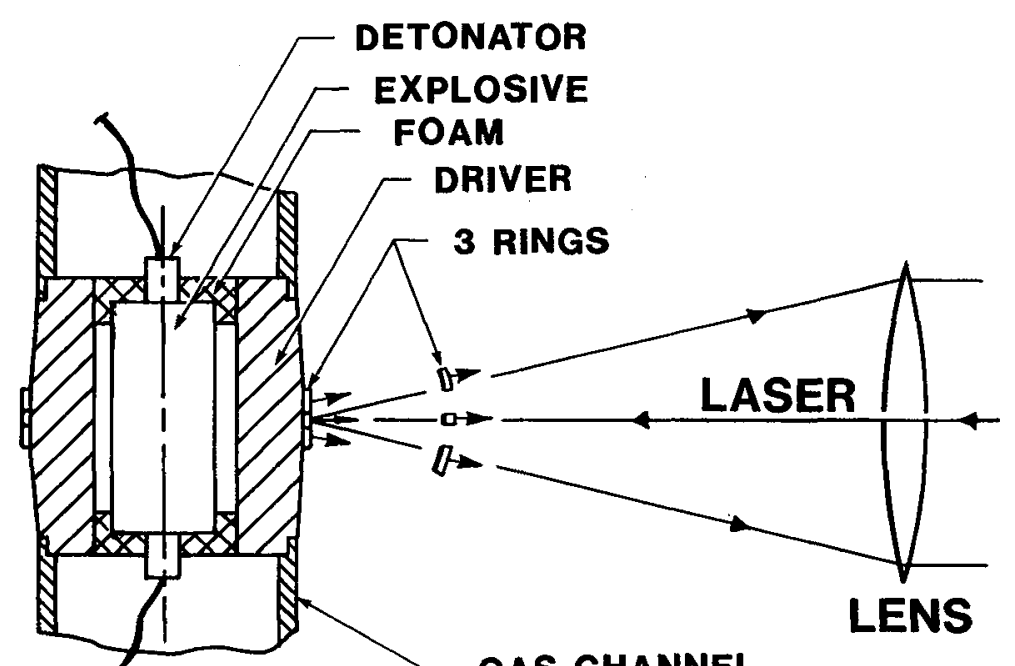

Fig. 1 - A schematic of the freely expanding ring test showing the three rings before and after launch from the driver.

The ring launching velocity, and, therefore, the strain rate, can be varied over a large range by varying the explosive diameter--see Eq. (3). Another way to increase the strain rate is to scale down the dimensions of the experiment. Nearly the same launch velocity is obtained in scaled experiments as long as the explosive is scaled too. Experiments have been scaled up by a factor of two and down by a factor of four from the standard driver.

III - CHOICE OF MATERIAL

The laser interferometer is capable of measuring such detail in the ring's motion that batch-to-batch, and even in-batch, variations in the raw material from which the rings are made can be seen. Therefore, to see if the test warrants confidence as a reliable tool in determining materials properties, close control of the ring material was necessary. For these tests OFE fully annealed copper from the same batch was chosen. Choice of this material also allowed a detailed comparison with al ready existing data taken on the Hopkinson bar.

\section{IV - THE EXPERIMENTS}

Twenty-three experiments have been conducted in this series. On most of them the explosive was detonated on both ends simultaneously. On a few, however, only one detonator was used to see if the initial acceleration of the ring might be less severe. The recovered samples indicated that the launch of the rings on these latter tests, while possibly less severe, was not radial, resulting in the ring twisting in flight. These few tests have not been included in the data presented here.

The driver size and the explosive diameter were chosen to launch the rings at a strain rate of about $5 \times 10^{3} \mathrm{~s}^{-1}$, a convenient range for the Hopkinson bar.

Figure 2 is a plot of the data obtained on one of the experiments. The oscillatory region immediately after launch is the region of two-dimensional motion that the three-ring geometry was designed to minimize. It is not included in the subsequent 
analysis. The end of a useful record is determined by either the loss of light, the end of the recording oscilloscope trace, or the appearance of noise caused by explosive gases curling around into the laser's path or perturbations to the smooth motion of the ring (discussed below).

$V$ - DATA ANALVSIS

Figure 3 is a plot of the data to be analyzed from three sets of experiments, the sets differing only in the size of the explosive used. A number of different procedures have been used recently to determine the flow stress from the velocity-time data. Most have involved fitting the velocity-time data with a differentiable analytic function and applying Eq. (1) [4]. The velocity-time data does contain small, but measurable, perturbations to the ring motion believed to be caused by asymmetries of launch and localized yielding phenomena that generate disturbances travelling circumferentially in the ring. Because the differentiation causes the stress-strain data to be very sensitive to the velocity-time data, this procedure frequently gives results that are not realistic in the stress-strain plane. An alternate method that shows the most promise consists of assuming a familiar and/or simple form for the stress-strain relation and fitting the velocity history derived from it and Eq. 1 to the experimental data by the method of least squares. Several fitting forms have been used, with the most consistently reasonable results coming from the Voce (4) and the power (5) equations below:

$$
\begin{gathered}
\sigma=a+b e^{\varepsilon / c} \text { and } \\
\dot{\sigma}=a^{*}+b \varepsilon^{c} .
\end{gathered}
$$

Figure 4 shows the results of this analysis for the experiments. The scatter in the data from nearly identical experiments is believed to be a consequence of the small perturbations to the ring motion mentioned above. The strain rate in an ERT decreases during the experiment because $\dot{r}$ decreases faster than $r$ increases--see Eq. (3). This is not necessarily a disadvantage; several experiments can map out a stress-strain-strain-rate surface for a given material. However, it generally requires additional experiments to separate the effects of the decreasing strain rate and work hardening that are occurring simultaneousiy. The strain rates for

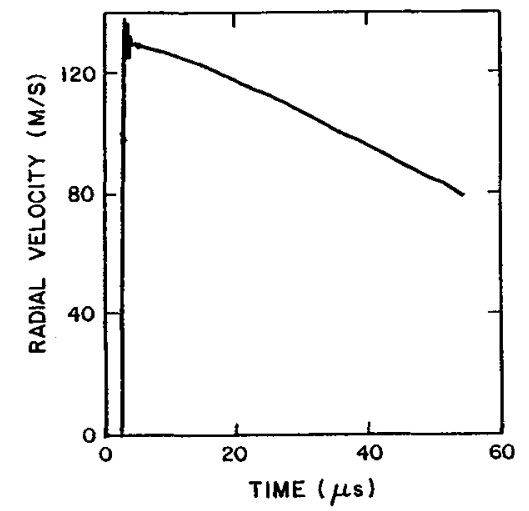

Fig. 2 - A typical velocity-time profile from one of the expanding ring experiments.

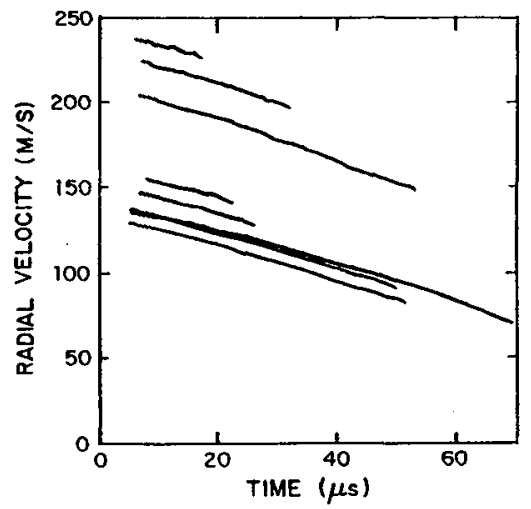

Fig. 3 - The analyzable portions of the velocity-time profile from eight 50.8-mm-diam expanding ring experiments. 


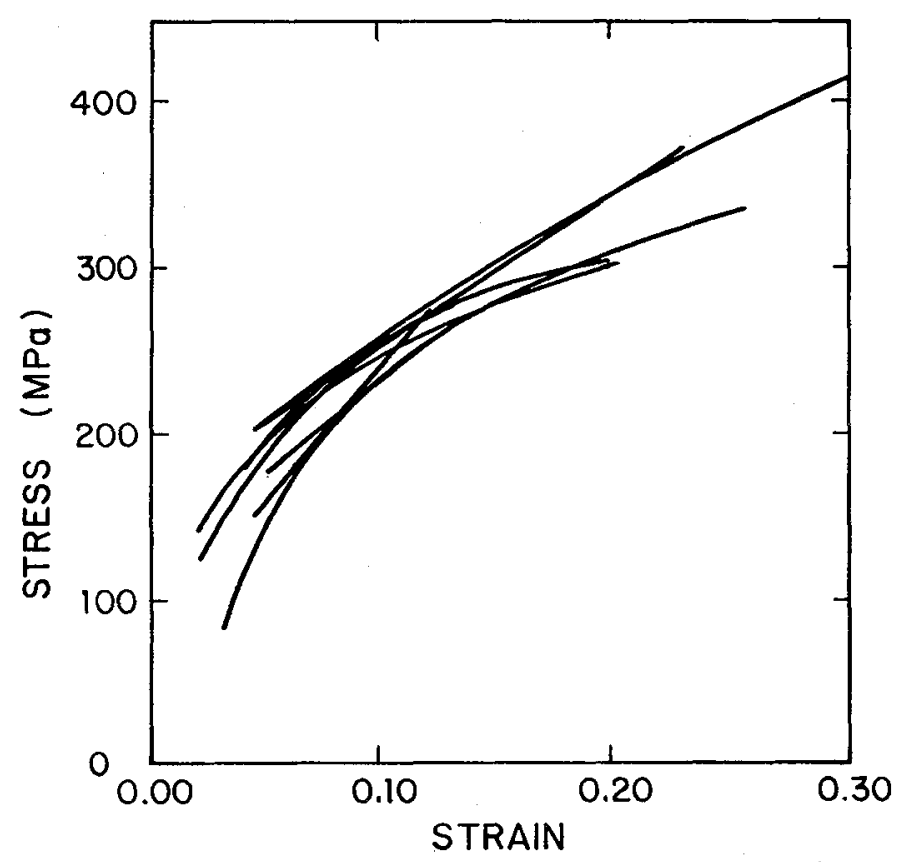

Fig. 4 - The stress-strain behavior of copper determined from the data shown in Fig. 3 and analyzed using Eq. (1) and either Eq. (4) or Eq. (5).

these data, measured in the middle of the data windows, ranged from 3.8 to $8.4 \times 10^{3} \mathrm{~s}^{-1}$.

VI - SHOCK HARDENING AND COMPARISONS WITH HOPKINSON BAR DATA

The ERT has been slow in gaining acceptance as a reliable tool for obtaining stress-strain data at large strains and high strain rates. This reluctance may be due to the unknown extent of shock wave hardening during the ring's launch from the driver. It had been noted that the recent ERT data from these well controlled experiments generally indicated larger flow stresses in the test material than similar data taken with other techniques. To see if shock wave hardening could be the cause of this discrepancy and to shed some light on the ERT launching process in general, several small segments of a ring of OFE fully annealed copper were launched in a standard experiment and recovered. Thus, samples were subjected to the through-thickness shock wave but to virtually no circumferential strain.

The recovered samples and a control of unshocked annealed material were given microhardness tests with the result that the diamond pyramid hardness (DPH) values for the shocked samples were $23 \%$ higher than those for the control sample. This suggests that a ring of this shock hardened material would exhibit a larger flow stress than a ring of the control material in an ERT.

To get a feeling for what amount of strain hardening would be equivalent to this amount of DPH increase, four annealed samples of the identical copper material were compressed statically (that is, compressed in one direction with the sides free to expand) to strains of $2 \%, 4 \%, 6 \%$, and $10 \%$ and their hardness measured. These data are plotted in Fig. 5. There is a correlation between the hardness increase in the shock hardened samples and the hardness one would expect from a sample strained 9\% staticaliy. While it is likely that the defect structure in the shock hardened 
samples is different from that in the statically compressed samples, it does give an indication of the amount of structural change effected by the passage of the shock wave.

The above tests indicate that the ERT data would correlate better with data from Hopkinson bar tests if the Hopkinson bar specimens were prestrained slightly. Figure 6 shows the stress-strain curve for a sample prestrained $5 \%$ in compression, unloaded, and then deformed in the Hopkinson bar at a strain rate of $5 \times 10^{3} \mathrm{~s}^{-1}$. Included on the plot are the Hopkinson bar data for a sample without prestrain. These data are compared with data from two selected ERTs at a strain rate of $4 \times 10^{3} \mathrm{~s}^{-1}$. Figure 7 is a plot of the ERT data from Fig. 4 along with the Hopkinson bar data from Fig. 6. Also included are stress-strain data on copper being deformed quasi-statically and ERT data taken at strain rates of 0.99 and $2.3 \times 10^{4} \mathrm{~s}^{-1}$. The fact that the $0.99 \times 10^{4} \mathrm{~s}^{-1}$ experiment has a higher flow stress than the $2.3 \times 10^{4} \mathrm{~s}^{-1}$ experiment is an indication of the precision to be expected in these experiments and emphasizes the desirability of conducting duplicate experiments. The agreement between the ERT data at the lower strain rates and the data from the Hopkinson bar test with the prestrained sample is quite good. This comparison at about $5 \times 10^{3} \mathrm{~s}^{-1}$ will permit the test to be used at the higher strain rates that can be achieved by scaling while being able to make at least a qualitative adjustment for the effect of shock hardening on the data.

These data provide some information on whether shock hardening differs from work hardening at ordinary strain rates. The hardness tests described above defined two very different loading paths that produced the same DPH increase. Using the von Mises yield condition, the work per unit volume required to achieve a $9 \%$ one-dimensional quasi-static compression of a sample with sides free to expand is $0.156 \mathrm{k}$, where $k$ is the yield point in simple shear. The work per unit volume done on a sample by the passage of the launching shock wave in the ERT (4.2 GPa), both loading and unloading, is $0.065 \mathrm{k}$, also obtained by applying the von Mises condition. This latter calculation assumes an Hugoniot Elastic Limit (HEL) of $[1+\lambda /(2 \mu)] \sqrt{3} k-$ no strain rate effects. These two calculations differ by a factor of 2.4, with the work in the dynamic path being the lower. Since actual HELs with rate effects are frequently larger than the HEL calculation without rate effects by. about this amount, the work in each path is nearly the same. Without considering the microstructural details of the two paths, these calculations suggest that hardening for a given amount of plastic work is about the same in the shock process as it is in ordinary quasi-static processes.

It should be noted that, while the shock hardening of the sample during its launch does add a complication to the use of ERT data to determine fundamental constitutive properties of materials, there are many applications for materials which involve

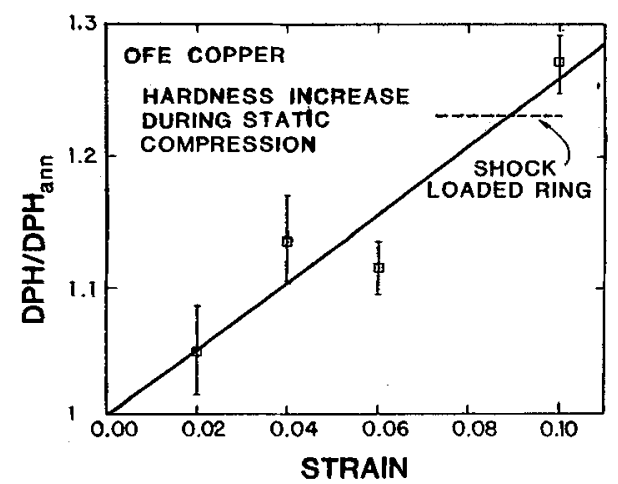

Fig. 5 - The relative $D P H$ increase as a function of prestrain in the copper samples.

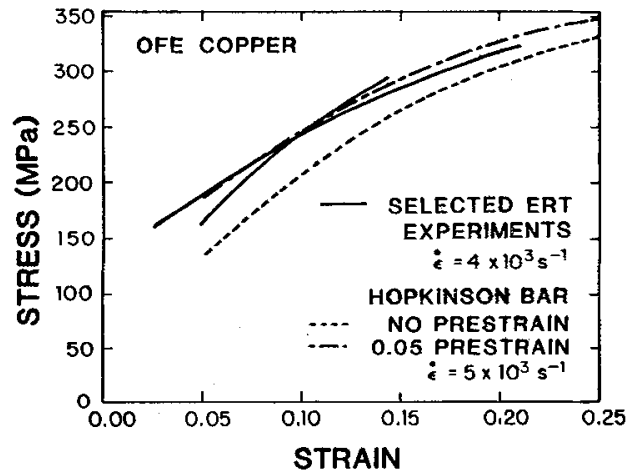

Fig. 6 - A comparison of stress-strain data from Hopkinson bar tests with data from two expanding ring tests. 


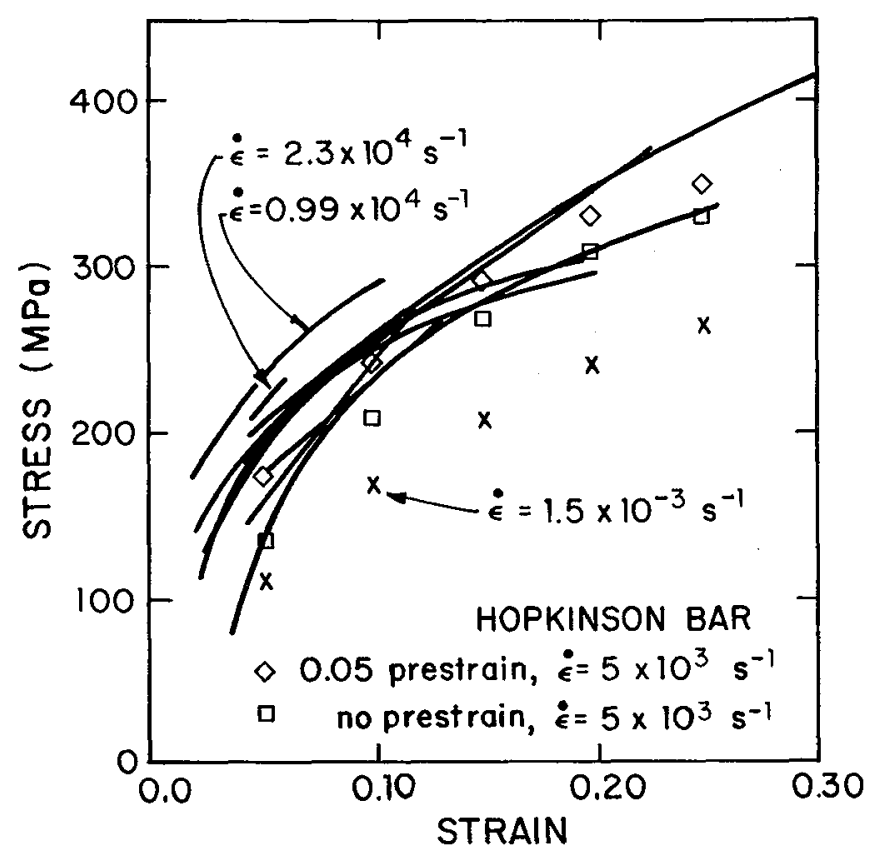

Fig. 7 - A comparison of stress-strain data from Hopkinson bar and expanding ring tests at strain rates of about $5 \times 10^{3} \mathrm{~s}^{-1}$ along with data taken at quasi-static strain rates for reference. In addition, data are shown from two scaled down expanding ring tests at strain rates of 0.99 and $2.3 \times 10^{4} \mathrm{~s}^{-1}$.

initial acceleration by shock waves followed by high strain rate deformation. For these problems the ERT, or any of its variations [5], can still provide stress-strain data at large strains and at strain rates not accessible by other techniques. The complication of shock hardening may be completely avoided by using non-explosive launching techniques. An electromagnetic system for the ERT has been discussed in reference [5].

\section{SUMMARY}

The ERT has been studied in detail, and a careful series of experiments on a well controlled material (OFE fully annealed copper) has been conducted at strain rates near $5 \times 10^{3} \mathrm{~s}^{-1}$. The effect of shock hardening on the measured ring motion has been determined by measuring the increase in hardness of shock-launched and recovered ring segments and then comparing the ERT data with Hopkinson bar data taken at the same strain rate on a sample that had been statically strained before the test. The comparison indicated that, in these experiments, the amount of shock hardening was equivalent to a statically-induced strain of $5 \%$. With this calibration, the test has been extended to strain rates of 0.99 and $2.3 \times 10^{4} \mathrm{~s}^{-1}$.

\section{ACKNOWLEDGMENTS}

The authors would like to thank J. M. Walsh and J. D. Jacobson for many discussions and Gerald Whittemore, Gilbert Sanchez, Gilbert Martinez, and Baudino Montoya for assembling and conducting the experiments. We are grateful to Elaine Alei for her many hours reading, analyzing, and plotting the data. 


\section{REFERENCES}

[1] P. C. Johnson, B. A. Stein, and R. S. Davis, "Measurement of Dynamic Plastic Flow Properties Under Uniform Stress," Symposium on the Dynamic Behavior of Materials, ASTM Special Publication No. 336, p. 195 (1963).

[2] C. R. Hoggatt and R. F. Recht, "Stress-Strain Data Obtained at High Rates Using an Expanding Ring," Exp. Mech., 9, 441 (1969).

[3] R. H. Warnes, T. A. Duffey, R. R. Karpp, and A. E. Carden, "An Improved Technique for Determining Dynamic Material Properties Using the Expanding Ring," Shock Waves and High-Strain-Rate Phenomena in Metals, Marc A. Meyers and Lawrence E. Murr, Eds. (PTlenum Press, New York, 1981), Chap. 2, p. 23.

[4] T. A. Duffey, R. R. Karpp, R. H. Warnes, J. D. Jacobson, and A. E. Carden, "Dynamic Material Property Measurements Using an Improvement of the Freely Expanding Ring," Experimental Techniques, 5, No. 4 (1981).

[5] R. H. Warnes, R. R. Karpp, T. A. Duffey, A. E. Carden, and J. D. Jacobson, "Development of the Freely Expanding Ring Test for Measuring Dynamic Material Properties," Proceedings of the 1982 Joint Conference on Experimental Mechanics, Oahu-Maui, Hawai, May 23-28, 1982 (SESA, Brookfield Center, CT), Part II. p. 656. 